Supporting Information

\title{
Revealing Reaction Pathways of Collective Substituted Iron Fluoride Electrode for Lithium Ion Batteries
}

Sooyeon Hwang ${ }^{1}$, Xiao $\mathrm{Ji}^{2}$, Seong-Min $\mathrm{Bak}^{3}$, Ke Sun ${ }^{4}$, Jianming Bai ${ }^{5}$, Xiulin $\mathrm{Fan}^{2}$, Hong Gan ${ }^{4}$, Chunsheng Wang ${ }^{2}$, Dong $\mathrm{Su}^{1,6, *}$

${ }^{1}$ Center for Functional Nanomaterials, Brookhaven National Laboratory, Upton, NY 11973, United States

${ }^{2}$ Department of Chemical and Biomolecular Engineering, University of Maryland, College Park, MD 20742, United States

${ }^{3}$ Chemistry Department, Brookhaven National Laboratory, Upton, NY 11973, United States

${ }^{4}$ Sustainable Energy Technologies Department, Brookhaven National Laboratory, Upton, NY 11973, United States

${ }^{5}$ National Synchrotron Light Source II, Brookhaven National Laboratory, Upton, NY 11973, United States

${ }^{6}$ Beijing National Laboratory for Condensed Matter Physics, Institute of Physics, Chinese Academy of Sciences, Beijing, 100190, China.

*Correspondence to D. Su (dongsu@iphy.ac.cn) 

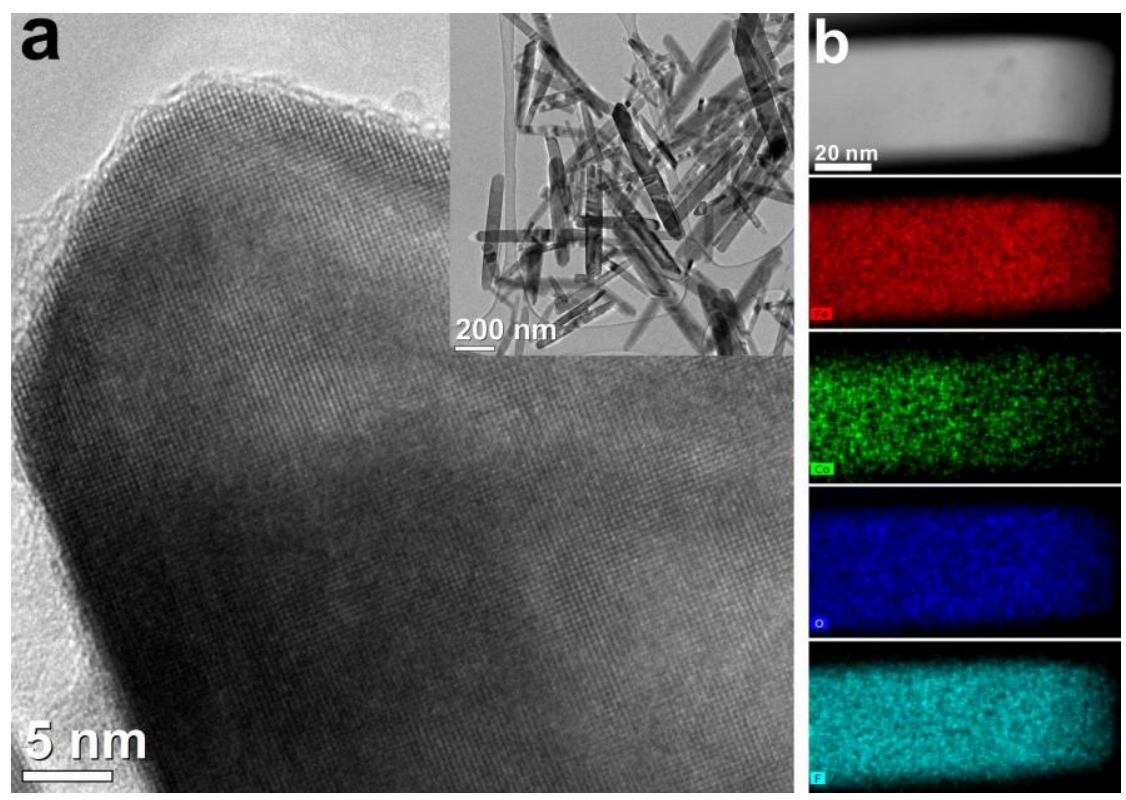

Figure S1. (a) a High-resolution TEM image of as-synthesized $\mathrm{Fe}_{0 .}{ }_{9} \mathrm{Co}_{0.1} \mathrm{OF}$ sample with an inset of lower-magnification bright-field image (b) a HAADF-STEM image and STEM-EDX elemental maps of $\mathrm{Fe}, \mathrm{Co}, \mathrm{O}, \mathrm{F}$ from as-synthesized $\mathrm{Fe} 0.9 \mathrm{Co} 0.1 \mathrm{OF}$ sample. 
(a) Pristine

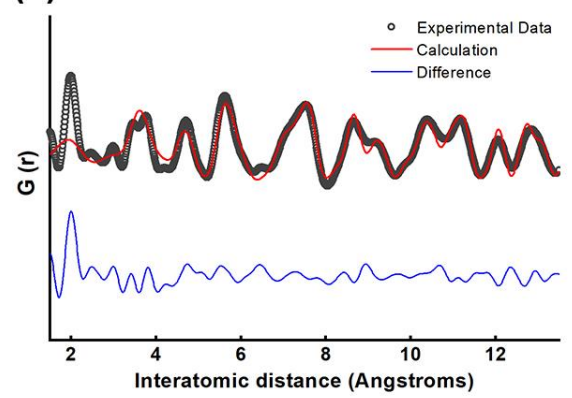

(c) $1.6 \mathrm{~V}$

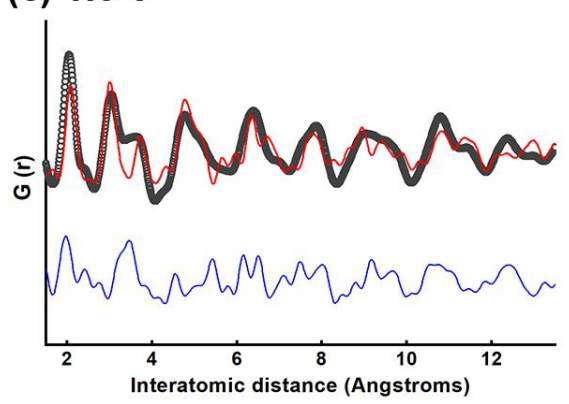

(e) $4.0 \mathrm{~V}$

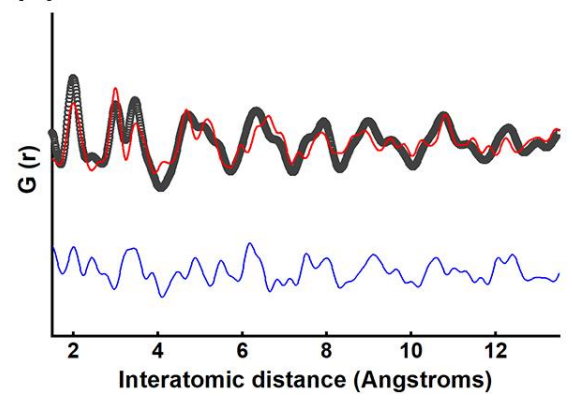

(b) $2.5 \mathrm{~V}$

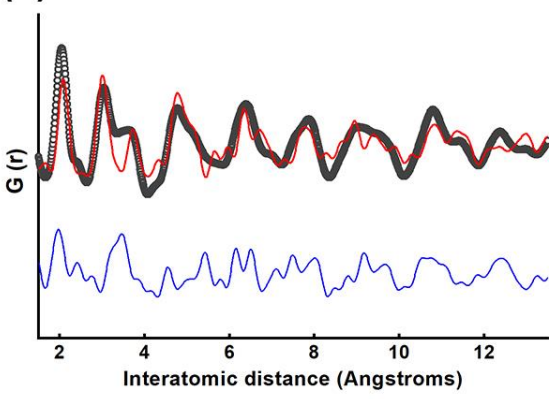

(d) $1.0 \mathrm{~V}$

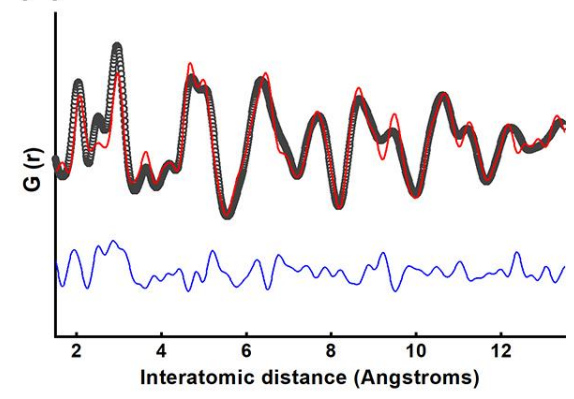

Figure S2. PDF fitting results with a function of cutting voltage. PDF fittings were performed based on attenuated crystal (AC) approximation using PDFgui. $\mathrm{R}_{\mathrm{w}}$ factor for each fit: (a) 0.49 (b) 0.62 (c) 0.64 (d) 0.39 (e) 0.64 . 


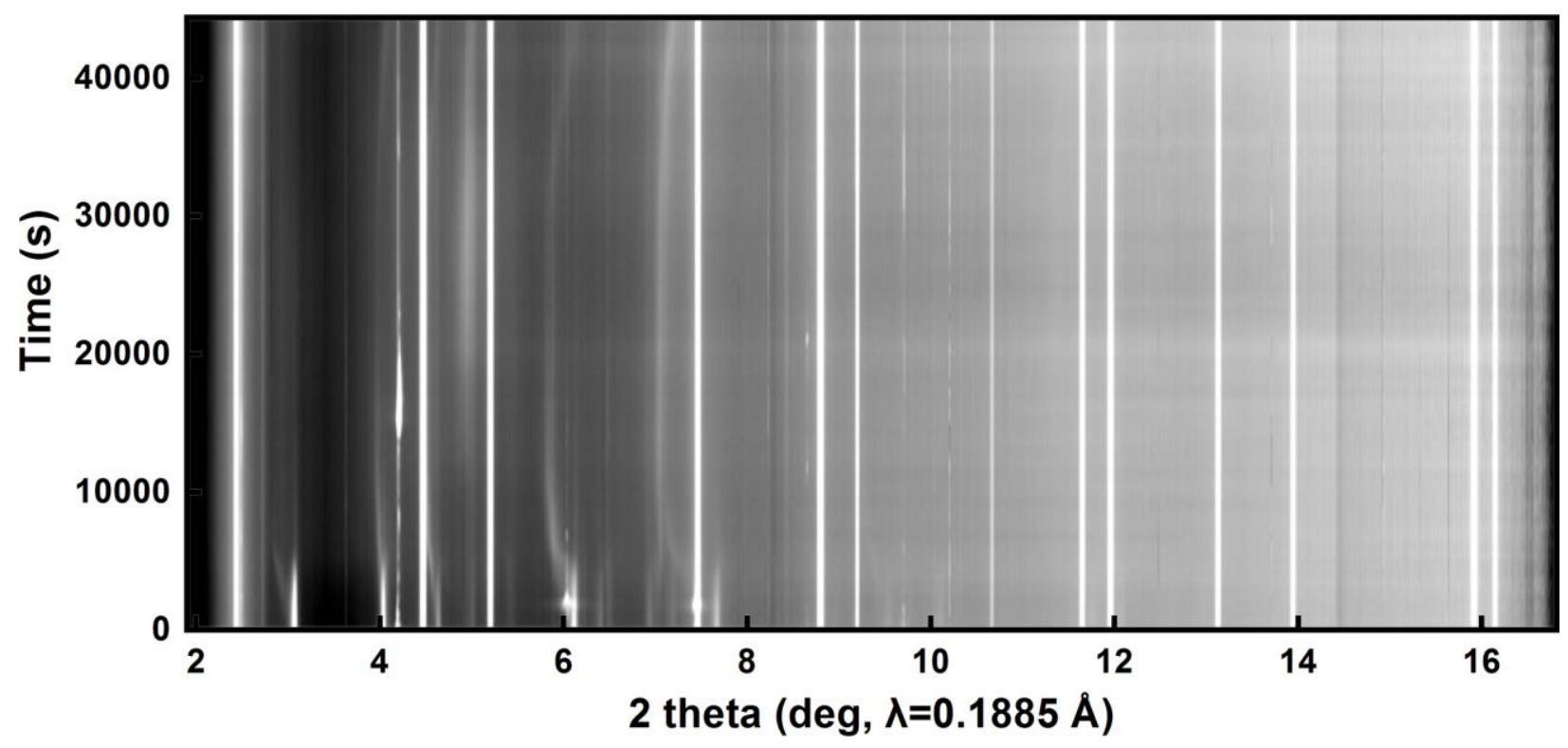

Figure S3. In situ X-ray diffraction pattern over the continuous 2 theta range. Background was subtracted using power-law function. Strong diffraction peaks at 4.65, 5.38, 7.60, 8.92, 9.32, 10.31, $11.74,12.04,13.19^{\circ}$ represent (111), (200), (220), (222), (400), (331), (420), (422) reflections from Al foil used for current collector. 

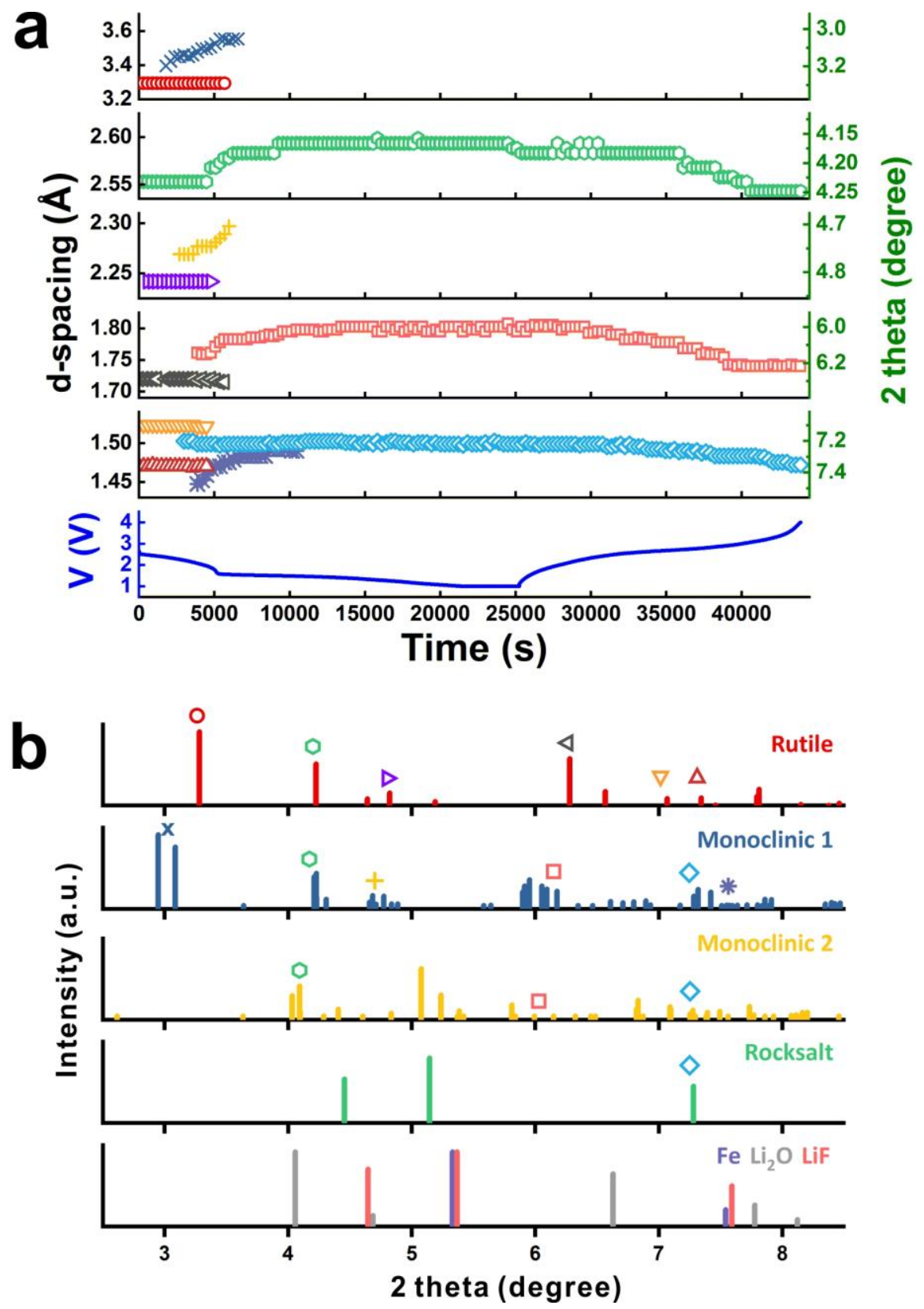

Figure S4. (a) Changes in d-spacings retrieved from the in situ XRD patterns in Figure 2. (b) Reference XRD patterns of well-known phases at ICSD collection (FeOF Rutile: Coll. Code 2875/ Fe: Coll. Code 53802/ Li2O: Coll. Code 22402/ LiF: Coll. Code 198097) and proposed phases (Monoclinic 1, monoclinic 2, rocksalt). Wavelength: $0.1885 \AA$ A. Symbols in (a) are marked in (b) at corresponding 2 theta degree. 

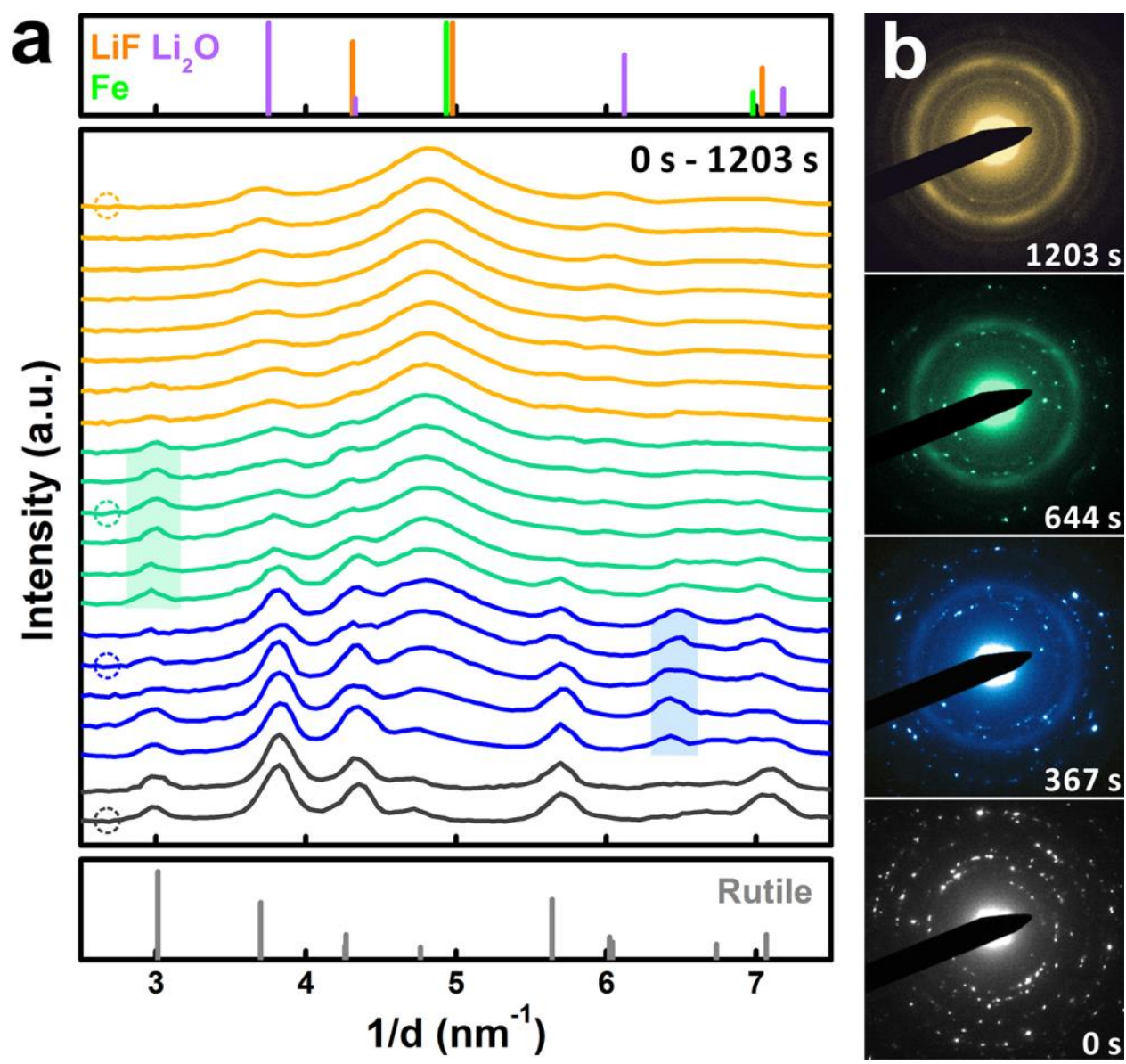

Figure S5. (a) Changes in intensity profiles of selected area electron diffraction (SAED) patterns during lithiation from Movie S2. Newly evolved peaks are highlighted. (b) Real-time SAED patterns. The acquisition times are marked with dashed circles in (a). 


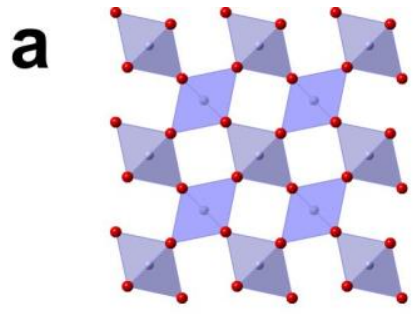

i) Rutile [001]

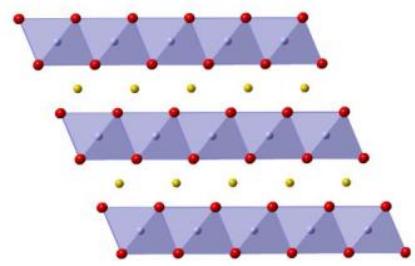

iv) $\mathrm{M} 2[110]$

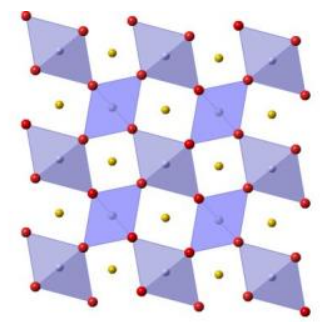

ii) M1 [010]

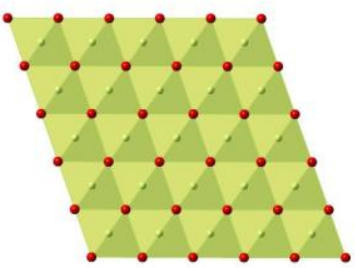

v) Rocksalt [110]

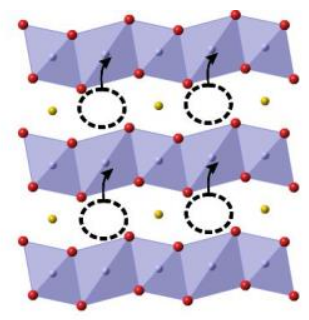

iii) M1 to M2

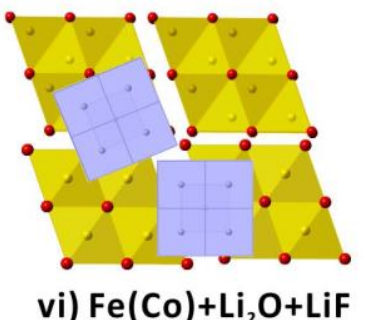

b

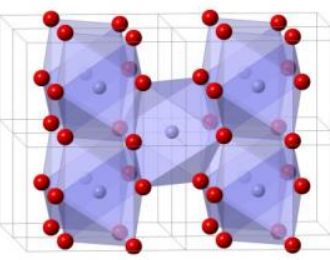

i) Rutile [100]

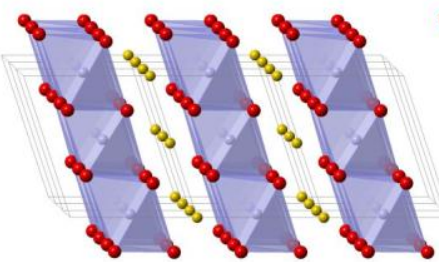

iv) $\mathrm{M} 2$ [010]

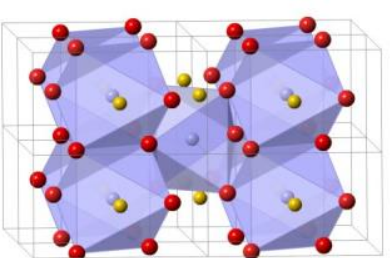

ii) M1 [100]

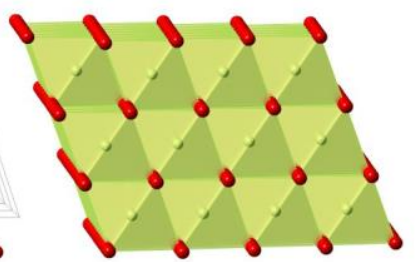

v) Rocksalt [110]

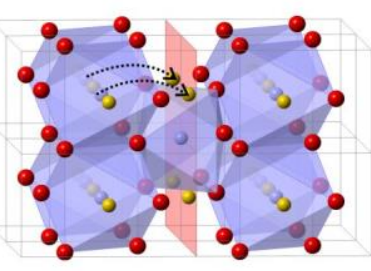

iii) $\mathrm{M} 1$ to $\mathrm{M} 2$

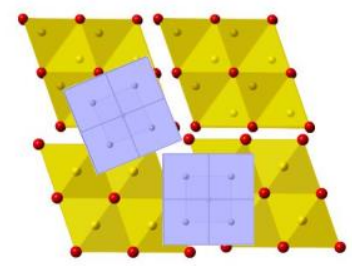

vi) $\mathrm{Fe}(\mathrm{Co})+\mathrm{Li}_{2} \mathrm{O}+\mathrm{LiF}$

Figure S6. Modifications of atomic rearrangement of FeCoOF during lithitation. 
(a)

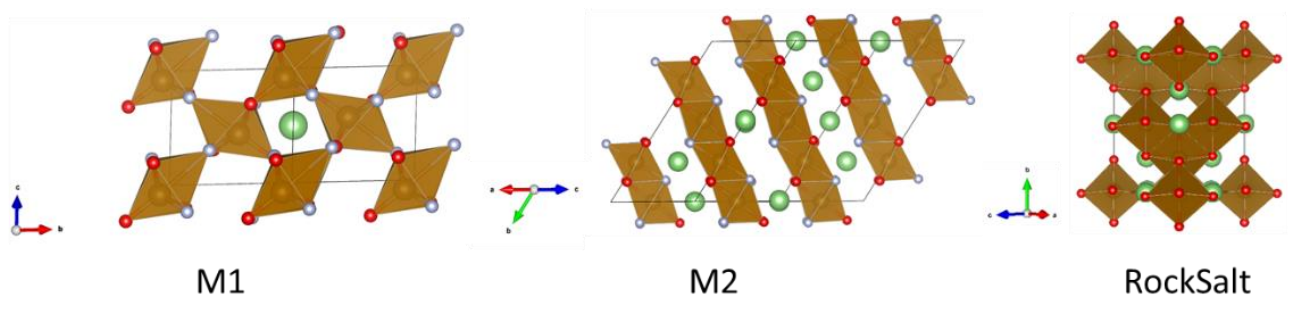

(b)

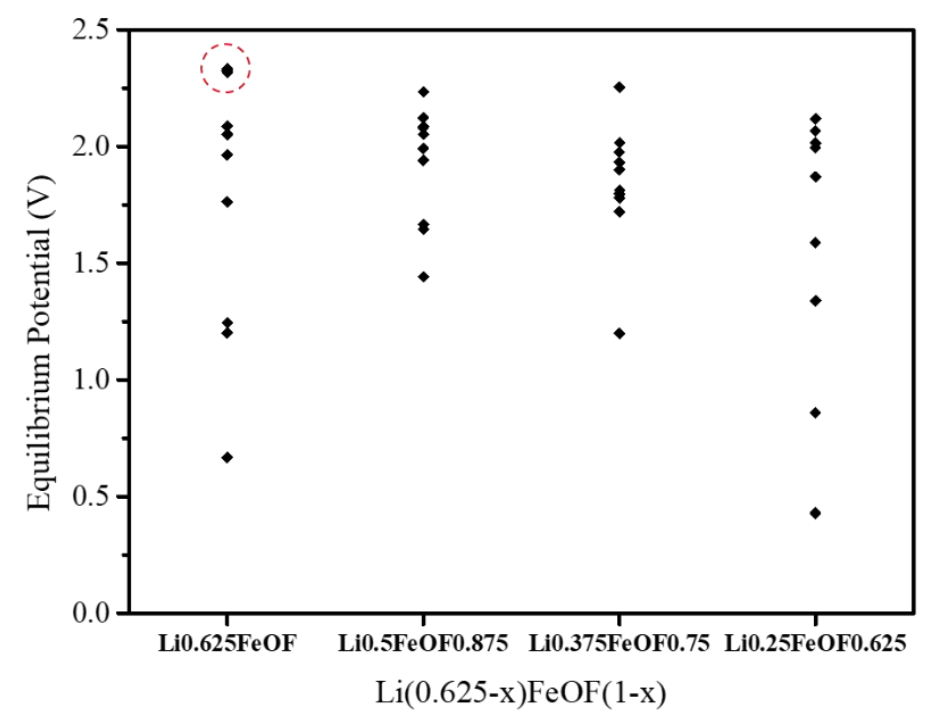

Figure S7. The DFT calculated (a) energy favorable ordered structures for M1, M2 and Rocksalt phases and (b) equilibrium potential for the $\mathrm{M} 2$ phase $\left(\mathrm{Li}_{(0.625-\mathrm{x})} \mathrm{FeOF}(1-\mathrm{x})\right)$ for $\mathrm{x}=0,0.125,0.25$, and 0.375. According to the experimental results, we assumed that the M2 phase has a formula of $\mathrm{Li}_{(0.625-\mathrm{x})} \mathrm{FeOF}_{(1-\mathrm{x})}$. Since the $\mathrm{x}$ is difficult to determined, based on the charging/discharging curves, we studied the cases for $\mathrm{x}=0,0.125,0.25$, and 0.375 . To order the structures, for each $\mathrm{x}$, structures were enumerated, and the ten electrostatic energy favorable structures obtained by sorting the Ewald summation energy were used to get accurate DFT energies, as detailed in the Method section. The DFT energies are used to predict the equilibrium potential by using Nernst equation. Under this definition, the higher potential stands for the more thermodynamic energy favorable phase. For all of the cases, the structure with the formula of $\mathrm{Li} 0.625 \mathrm{FeOF}$ as shown in the red dashed circle shows the highest potential. The red dashed circle indicated the potential used for the voltage profile. 


\section{Supporting tables}

Table S1. Nearest neighbor bonding length of Fe-O, Fe-F, Co-O, Co-F in a generated phase of $\mathrm{Fe}_{7} \mathrm{CoO}_{8} \mathrm{~F}_{8} . \mathrm{Fe}_{7} \mathrm{CoO}_{8} \mathrm{~F}_{8}$ phase is constructed to save the cost of the calculation but the general trend is same with the actual composition of $\mathrm{Fe}_{0.9} \mathrm{Co}_{0.1} \mathrm{OF}{ }^{1}$

\begin{tabular}{|c|c|}
\hline & Bonding length \\
\hline Fe-O & $1.9310 \AA$ \\
\hline Fe-F & $2.1078 \AA$ \\
\hline Co-O & $1.8819 \AA$ \\
\hline Co-F & $2.0118 \AA$ \\
\hline
\end{tabular}

Table S2. A summary of cycling performance of iron fluorides and their derivatives in lithium ion batteries.

\begin{tabular}{|c|c|c|c|c|c|}
\hline \multirow[b]{2}{*}{ Material } & \multicolumn{3}{|c|}{ Test conditions } & \multirow[b]{2}{*}{ Performance } & \multirow[b]{2}{*}{ Ref. } \\
\hline & $\begin{array}{l}\text { Voltage } \\
\text { window }\end{array}$ & Rate & $\begin{array}{l}\# \text { of } \\
\text { cycles }\end{array}$ & & \\
\hline $\mathrm{FeF}_{3}$ & $1.7-4.0 \mathrm{~V}$ & $50 \mathrm{~mA} \mathrm{~g}^{-1}$ & 50 & $\begin{array}{l}\text { 71.64\% of initial capacity (144 mA } \\
\left.\mathrm{g}^{-1}\right)\end{array}$ & 2 \\
\hline \multirow[t]{2}{*}{$\mathrm{FeF}_{3} / \mathrm{rGO}$} & $1.0-4.5 \mathrm{~V}$ & $50 \mathrm{~mA} \mathrm{~g}^{-1}$ & 50 & $\begin{array}{l}25.84 \% \text { of initial capacity }(123 \mathrm{~mA} \\
\left.\qquad \mathrm{g}^{-1}\right)\end{array}$ & \multirow[t]{2}{*}{3} \\
\hline & $1.7-4.5 \mathrm{~V}$ & $500 \mathrm{~mA} \mathrm{~g}^{-1}$ & 50 & $89 \%$ of initial capacity $\left(134 \mathrm{~mA} \mathrm{~g}^{-1}\right)$ & \\
\hline $\mathrm{FeF}_{3}$ & $1.5-4.5 \mathrm{~V}$ & $50 \mathrm{~mA} \mathrm{~g}^{-1}$ & 50 & $\begin{array}{l}41.06 \% \text { of initial capacity }(223 \mathrm{~mA} \\
\left.\qquad \mathrm{g}^{-1}\right)\end{array}$ & 4 \\
\hline $\mathrm{FeF}_{2} @ \mathrm{CNT}$ & $1.0-4.2 \mathrm{~V}$ & $100 \mathrm{~mA} \mathrm{~g}^{-1}$ & 50 & $\begin{array}{c}81.9 \% \text { of initial capacity }\left(181 \mathrm{~mA} \mathrm{~g}^{-}\right. \\
1 \text { ) }\end{array}$ & 5 \\
\hline $\mathrm{C}\left(\mathrm{FeF}_{2}\right)_{0.55}$ & $1.3-4.3 \mathrm{~V}$ & $\underset{1}{22.7 \mathrm{~mA} \mathrm{~g}^{-}}$ & 25 & $\begin{array}{l}56.77 \% \text { of initial capacity }(327 \mathrm{~mA} \\
\left.\mathrm{g}^{-1}\right)\end{array}$ & 6 \\
\hline $\mathrm{FeF}_{2} / \mathrm{C}$ & $1.3-4.2 \mathrm{~V}$ & $30 \mathrm{~mA} \mathrm{~g}^{-1}$ & 50 & $\begin{array}{c}69.1 \% \text { of initial capacity }\left(217 \mathrm{~mA} \mathrm{~g}^{-}\right. \\
\left.{ }^{1}\right)\end{array}$ & 7 \\
\hline $\mathrm{FeF}_{2}$ (thin film) & $0.01-4 \mathrm{~V}$ & $5 \mu \mathrm{A} \mathrm{cm}^{-2}$ & 5 & $35 \%$ of initial capacity & \\
\hline $\mathrm{FeOF}$ (thin film) & $0.01-4 \mathrm{~V}$ & $5 \mu \mathrm{A} \mathrm{cm}^{-2}$ & 40 & $60 \%$ of initial capacity & \\
\hline $\mathrm{FeOF}$ & $1.3-4 \mathrm{~V}$ & $60 \mathrm{~mA} \mathrm{~g}^{-1}$ & 30 & $\sim 300 \mathrm{~mA} \mathrm{~g}^{-1}$ & 9 \\
\hline
\end{tabular}




\begin{tabular}{|c|c|c|c|c|c|}
\hline $\mathrm{FeOF}$ & $2.0-3.8 \mathrm{~V}$ & $100 \mathrm{~mA} \mathrm{~g}^{-1}$ & 100 & Below $50 \%$ of initial capacity & \multirow{2}{*}{10} \\
\hline PEDOT coated FeOF & $2.0-3.8 \mathrm{~V}$ & $100 \mathrm{~mA} \mathrm{~g}^{-1}$ & 200 & About $75 \%$ of initial capacity & \\
\hline FeOF@PEDOT & $1.2-4.0 \mathrm{~V}$ & $50 \mathrm{~mA} \mathrm{~g}^{-1}$ & 150 & $94 \%$ of initial capacity $\left(407 \mathrm{~mA} \mathrm{~g}^{-1}\right)$ & 11 \\
\hline \multirow{3}{*}{$\mathrm{FeF}_{3} / \mathrm{C}$} & \multirow{3}{*}{$2.0-4.5 \mathrm{~V}$} & $1 \mathrm{C}$ & \multirow{3}{*}{100} & $\begin{array}{l}78.8 \% \text { of initial capacity }(101.9 \mathrm{~mA} \\
\left.\qquad \mathrm{g}^{-1}\right)\end{array}$ & \multirow{6}{*}{12} \\
\hline & & $2 \mathrm{C}$ & & $\begin{array}{c}70.3 \% \text { of initial capacity }\left(83.6 \mathrm{~mA} \mathrm{~g}^{-}\right. \\
\left.{ }^{1}\right)\end{array}$ & \\
\hline & & $5 \mathrm{C}$ & & $\begin{array}{c}67.7 \% \text { of initial capacity }\left(71.2 \mathrm{~mA} \mathrm{~g}^{-}\right. \\
1 \text { ( ) }\end{array}$ & \\
\hline \multirow{3}{*}{$\mathrm{Fe}_{0.95} \mathrm{Co}_{0.05} \mathrm{~F}_{3} / \mathrm{C}$} & \multirow{3}{*}{$2.0-4.5 \mathrm{~V}$} & $1 \mathrm{C}$ & \multirow{3}{*}{100} & $\begin{array}{l}92 \% \text { of initial capacity }(\sim 139.5 \mathrm{~mA} \\
\left.\qquad \mathrm{g}^{-1}\right)\end{array}$ & \\
\hline & & $2 \mathrm{C}$ & & $\begin{array}{l}92.2 \% \text { of initial capacity }(\sim 125.7 \\
\left.\mathrm{mA} \mathrm{g}^{-1}\right)\end{array}$ & \\
\hline & & $5 \mathrm{C}$ & & $\begin{array}{l}91.7 \% \text { of initial capacity }(\sim 117 \mathrm{~mA} \\
\left.\qquad \mathrm{g}^{-1}\right)\end{array}$ & \\
\hline $\mathrm{Fe}_{0.9} \mathrm{Co}_{0.1} \mathrm{OF}$ & $1.2-4.0 \mathrm{~V}$ & $500 \mathrm{~mA} \mathrm{~g}^{-1}$ & 1000 & Reversible capacity of $350 \mathrm{~mA} \mathrm{~g}^{-1}$ & 1 \\
\hline $\mathrm{FeF}_{3} \cdot 0.5 \mathrm{H}_{2} \mathrm{O}$ & $1.7-4.5 \mathrm{~V}$ & $0.1 \mathrm{C}$ & 300 & Discharge capacity of $114 \mathrm{~mA} \mathrm{~g}^{-1}$ & 13 \\
\hline $\mathrm{FeF}_{3} \cdot 0.33 \mathrm{H}_{2} \mathrm{O}$ & $2.0-4.5 \mathrm{~V}$ & $5 \mathrm{C}$ & 100 & $\begin{array}{l}83.3 \% \text { of initial capacity } \\
\qquad\left(87.6 \mathrm{~mA} \mathrm{~g}^{-1}\right)\end{array}$ & 14 \\
\hline $\mathrm{Fe}_{0.9} \mathrm{Co}_{0.1} \mathrm{~F}_{3} \cdot 0.5 \mathrm{H}_{2} \mathrm{O}$ & $1.8-4.5 \mathrm{~V}$ & $0.1 \mathrm{C}$ & 200 & Discharge capacity of $150 \mathrm{~mA} \mathrm{~g}^{-1}$ & 15 \\
\hline $\mathrm{Fe}_{0.92} \mathrm{Ti}_{0.08} \mathrm{~F}_{3} \cdot 0.33 \mathrm{H}_{2} \mathrm{O}$ & $1.5-4.5 \mathrm{~V}$ & $0.1 \mathrm{C}$ & 40 & Discharge capacity of $294.86 \mathrm{~mA} \mathrm{~g}^{-1}$ & 16 \\
\hline
\end{tabular}

\section{Supporting movies}

Movie S1. In situ BF video showing lithiation reactions in a FeCoOF nanowire. Still shots are shown in Figure 3(a) in the manuscript. The video was accelerated by 20 times.

Movie S2. In situ SAED video showing lithiation reactions in a FeCoOF nanowire. Still shots are shown in Figure 3(a) in the manuscript. The video was accelerated by 83 times.

Movie S3. In situ HRTEM video showing lithiation reactions in a FeCoOF nanowire. Still shots are shown in Figure 3(a) in the manuscript. The video was accelerated by 15 times. 


\section{Supporting references}

(1) Fan, X.; Hu, E.; Ji, X.; Zhu, Y.; Han, F.; Hwang, S.; Liu, J.; Bak, S.; Ma, Z.; Gao, T.; Liuo, S.-Z.; Bai, J.; Yang, X.-Q.; Mo, Y.; Xu, K.; Su, D.; Wang, C. High EnergyDensity and Reversibility of Iron Fluoride Cathode Enabled via an IntercalationExtrusion Reaction. Nat. Commun. 2018, 9, 2324.

(2) Chu, Q.; Xing, Z.; Tian, J.; Ren, X.; Asiri, A. M.; Al-Youbi, A. O.; Alamry, K. A.; Sun, $\mathrm{X}$. Facile Preparation of Porous $\mathrm{FeF}_{3} \mathrm{Nanospheres}$ as Cathode Materials for Rechargeable Lithium-Ion Batteries. J. Power Sources 2013, 236, 188-191.

(3) Chu, Q.; Xing, Z.; Ren, X.; Asiri, A. M.; Al-Youbi, A. O.; Alamry, K. A.; Sun, X. Reduced Graphene Oxide Decorated with $\mathrm{FeF}_{3}$ Nanoparticles: Facile Synthesis and Application as a High Capacity Cathode Material for Rechargeable Lithium Batteries. Electrochim. Acta 2013, 111, 80-85.

(4) Li, L.; Meng, F.; Jin, S. High-Capacity Lithium-Ion Battery Conversion Cathodes Based on Iron Fluoride Nanowires and Insights into the Conversion Mechanism. Nano Lett. 2012, 12, 6030-6037.

(5) Zhou, J.; Zhang, D.; Zhang, X.; Song, H.; Chen, X. Carbon-Nanotube-Encapsulated $\mathrm{FeF}_{2}$ Nanorods for High-Performance Lithium-Ion Cathode Materials. ACS Appl. Mater. Interfaces 2014, 6, 21223-21229.

(6) Reddy, M. A.; Breitung, B.; Chakravadhanula, V. S. K.; Wall, C.; Engel, M.; Kübel, C.; Powell, A. K.; Hahn, H.; Fichtner, M. CFx Derived Carbon-FeF2 Nanocomposites for Reversible Lithium Storage. Adv. Energy Mater. 2012, 3, 308-313.

(7) Zhang, Y.; Wang, L.; Li, J.; Wen, L.; He, X. A One-Pot Approach Towards FeF2Carbon Cor-Shell Composite and Its Application in Lithium Ion Batteries. J. Alloys Compd. 2014, 606, 226-230.

(8) Le Yu; Wang, H.-X.; Liu, Z.-Y.; Fu, Z.-W. Pulsed Laser Deposited FeOF as Negative Electrodes for Rechargeable Li Batteries. Electrochim. Acta 2010, 56, 767-775.

(9) Kitajou, A.; Komatsu, H.; Nagano, R.; Okada, S. Synthesis of FeOF Using RollQuenching Method and the Cathode Properties for Lithium-Ion Battery. J. Power Sources 2013, 243, 494-498.

(10) Wang, L.-P.; Wang, T.-S.; Zhang, X.-D.; Liang, J.-Y.; Jiang, L.; Yin, Y.-X.; Guo, Y.-G.; Wang, C.-R. Iron Oxyfluorides as Lithium-Free Cathode Materials for Solid-State Li Metal Batteries. J. Mater. Chem. A 2017, 5, 18464-18468.

(11) Fan, X.; Luo, C.; Lamb, J.; Zhu, Y.; Xu, K.; Wang, C. PEDOT Encapsulated FeOF Nanorod Cathodes for High Energy Lithium-Ion Batteries. Nano Lett. 2015, 15, 76507656.

(12) Liu, L.; Zhou, M.; Yi, L.; Guo, H.; Tan, J.; Shu, H.; Yang, X.; Yang, Z.; Wang, X. Excellent Cycle Performance of $\mathrm{Co}-\mathrm{Doped} \mathrm{FeF}_{3} / \mathrm{C}$ Nanocomposite Cathode Material for Lithium-Ion Batteries. J. Mater. Chem. 2012, 22, 17539-17550. 
(13) Li, C.; Yin, C.; Gu, L.; Dinnebier, R. E.; Mu, X.; van Aken, P. A.; Maier, J. An $\mathrm{FeF}_{3} \cdot 0.5 \mathrm{H}_{2} \mathrm{O}$ Polytype: A Microporous Framework Compound with Intersecting Tunnels for Li and Na Batteries. J. Am. Chem. Soc. 2013, 135, 11425-11428.

(14) Liu, L.; Guo, H.; Zhou, M.; Wei, Q.; Yang, Z.; Shu, H.; Yang, X.; Tan, J.; Yan, Z.; Wang, X. A Comparison Among $\mathrm{FeF}_{3} \cdot 3 \mathrm{H}_{2} \mathrm{O}, \mathrm{FeF}_{3} \cdot 0.33 \mathrm{H}_{2} \mathrm{O}$ and $\mathrm{FeF}_{3}$ Cathode Materials for Lithium Ion Batteries: Structural, Electrochemical, and Mechanism Studies. J. Power Sources 2013, 238, 501-515.

(15) Ali, G.; Rahman, G.; Chung, K. Y. Cobalt-Doped Pyrochlore-Structured Iron Fluoride as a Highly Stable Cathode Material for Lithium-Ion Batteries. Electrochim. Acta 2017, 238, 49-55.

(16) Wei, S.; Wang, X.; Yu, R.; Zhang, R.; Liu, M.; Yang, Z.; Hu, H. Ti-Doped $\mathrm{Fe}_{1-\mathrm{x}} \mathrm{Ti}_{\mathrm{x}} \mathrm{F}_{3} \cdot 0.33 \mathrm{H}_{2} \mathrm{O} / \mathrm{C}$ Nanocomposite as an Ultrahigh Rate Capability Cathode Materials of Lithium Ion Batteries. J. Alloys Compd. 2017, 702, 372-380. 